\title{
FTIR INVESTIGATION ON CRYSTALLINITY OF HYDROXYPROPYL METHYL CELLULOSE-BASED POLYMERIC BLENDS
}

\author{
MIRELA-FERNANDA ZALTARIOV \\ Department of Inorganic Polymers, "Petru Poni" Institute of Macromolecular Chemistry, \\ 41A, Gr. Ghica-Voda Alley, 700487, Iasi, Romania \\ $\square$ Corresponding author: zaltariov.mirela@icmpp.ro
}

Received August 2, 2021

\begin{abstract}
Two series of polymeric blends have been prepared based on hydroxypropyl methyl cellulose (HPMC)/polyacrylic acid (PAA) $(1: 1,1: 2,1: 3,1: 4)$ and HPMC/sodium alginate (SA) $(1: 30,2: 30,3: 30,4: 30)$ and investigated by Attenuated Total Reflectance-Fourier Transform Infrared Spectroscopy (ATR-FTIR). IR analysis confirmed the interaction between the polymeric components in the blend and the degree of structural organization. Crystallinity changes in the blends were observed as a function of a number of experimental parameters, such as temperature, composition and HPMC concentration, by determining the quantitative crystallinity indexes: Total Crystallinity Index (TCI), Lateral Order Index (LOI) and Hydrogen Bond Index (HBI).
\end{abstract}

Keywords: hydroxypropyl methyl cellulose, polymeric blends, crystallinity, FTIR spectroscopy

\section{INTRODUCTION}

Hydroxypropyl methyl cellulose is a cellulose derivative obtained by methyl and hydroxypropyl substitution of free hydroxyl groups, with enhanced solubility, gelation and film-forming ability. Considering its properties, it has been investigated for use in oral and topical pharmaceutical applications, as mucoadhesive drug delivery system, specifically due to its high hydrophilicity, as well as in coating materials. ${ }^{1}$ In order to improve its mucoadhesive and physical properties, HPMC is used in combination with compatible polymeric components to form polymeric blends. Thus, a HPMC/PC blend film proved higher mucoadhesive properties than the pure HPMC film in buccal drug delivery systems. $^{2}$ Also, HPMC/PVP blends are more flexible, being suitable for applications in packanging, ${ }^{3}$ controlled drug delivery, ${ }^{4}$ tablet coating systems, ${ }^{5}$ while HPMC/chitosan blends could be a promising approach for transdermal drug delivery formulations. ${ }^{6}$

Studies on the morphology and crystallinity of cellulosic materials have been developed in recent years by means of infrared spectroscopy, Raman spectroscopy, solid state NMR and X-ray diffraction analysis, by defining the "total crystallinity index", "lateral order index" ${ }^{\prime 8}$ and "hydrogen bond intensity", 9 referring to the degree of the intermolecular regularity, crystal system and bound water.

Recently, the crystallinity index has been used to investigate the structural changes occurring in some cellulose derivatives after physicochemical or biological treatments. ${ }^{10-13}$

In this study, we prepared polymeric blends based on hydroxypropyl methyl cellulose (HPMC)/polyacrylic acid (PAA) and HPMC/sodium alginate (SA), in different ratios, and then used infrared spectroscopy to investigate in depth the influence of composition, concentration of hydroxypropyl methyl cellulose and temperature on the crystallinity of the developed polymeric blends.

\section{EXPERIMENTAL Materials}

Hydroxypropyl methyl cellulose (HPMC) (Aldrich, Germany), polyacrylic acid (PAA) (Aldrich, Germany) and sodium alginate (SA) (Aldrich, Germany) were used as received. The polymeric blends Ia (HPMC/PAA 1:1), Ib (HPMC/PAA 2:1), Ic (HPMC/PAA 3:1), Id (HPMC/PAA 4:1) and IIa (HPMC/SA 1:30), IIb (HPMC/SA 2:30), IIc (HPMC/SA 3:30), IId (HPMC/SA 4:30) were prepared according to a procedure described by Gafitanu. ${ }^{14}$ 


\section{Methods}

Attenuated Total Reflectance-Fourier Transform Infrared Spectroscopy (ATR-FTIR) recordings were carried out on a Bruker Vertex 70 spectrometer, equipped with a single reflection diamond ATR Golden Gate and a temperature controller. The spectra were recorded in the $600-4000 \mathrm{~cm}^{-1}$ spectral range, with a resolution of $2 \mathrm{~cm}^{-1}$, in the ATR mode.

The polymeric blends were analyzed first at room temperature and then at $37{ }^{\circ} \mathrm{C}, 47^{\circ} \mathrm{C}$ and $55^{\circ} \mathrm{C}$ (first step of thermal decomposition) in heating/cooling processes. After setting the temperature, the blend sample was maintained $3 \mathrm{~min}$ before the spectral acquisition. The $1500-1200 \mathrm{~cm}^{-1}$ spectral region was the most investigated one, as in this region, the characteristic bands assigned to the crystalline areas in the HPMC blend component were identified. The spectra were deconvoluted in this region by a fitting procedure, using OPUS 6.5 software, based on maxima found with the second derivative of the spectra. The corresponding areas of the peaks were calculated with a $50 \%$ Gaussian and 50\% Lorentzian function.

\section{RESULTS AND DISCUSSION}

In 1964, Nelson and O'Connor ${ }^{7}$ demonstrated that the ratio between the absorbance of the bands at $1372 \mathrm{~cm}^{-1}$ and $2900 \mathrm{~cm}^{-1}$ is useful to estimate the crystallinity in cellulose-based materials. They compared the infrared ratios of some cellulosic samples with the values obtained by X-ray diffractograms and found a good correlation with $\mathrm{X}$-ray data. Based on their reports, the most important region of the IR spectra is between $1500-1200 \mathrm{~cm}^{-1}$, as it is the wavenumber range where the characteristic bands assigned to $\mathrm{C}-\mathrm{H}$ bending, $\mathrm{O}-\mathrm{H}$ bending and $\mathrm{CH}_{2}$ wagging vibrations are found. Within this range, the most suitable in indicating the crystallinity is the 1372 $\mathrm{cm}^{-1}$ band. The ratio between this band and that at $2920 \mathrm{~cm}^{-1}$ (C-H stretching vibration) defines the Total Crystallinity Index (TCI). Another characteristic band is that at $1410 \mathrm{~cm}^{-1}$, assigned to $\mathrm{CH}_{2}$ scissoring vibrations, useful in the identification of the type of crystalline cellulose. The position and the intensity of this band are related to the structural modifications occurring at the C6 group (inter- and intramolecular $\mathrm{H}$ bonds), indicating the transition of crystalline cellulose to amorphous cellulose. ${ }^{8}$ The ratio of this band and that at $912 \mathrm{~cm}^{-1}$, which is attributed to the amorphous regions of the cellulose, defines the Lateral Order Index (LOI), which can be useful for assessing both qualitative and quantitative changes in cellulose crystallinity - when LOI decreases, the crystallinity also decreases.
Another way to predict the crystallinity of cellulosic materials is Hydrogen Bond Index (HBI). The ratio between the absorbance of the bands at $3350 \mathrm{~cm}^{-1}$, assigned to $\mathrm{O}-\mathrm{H}$ stretches, and that at $1330 \mathrm{~cm}^{-1}$, specific to the $\mathrm{O}-\mathrm{H}$ in-plane bending vibrations, can measure qualitative changes in crystallinity, because the band at 1330 $\mathrm{cm}^{-1}$ shows the greatest differences between the crystalline and the amorphous cellulose. ${ }^{15}$

\section{Influence of composition of HPMC-based polymeric blends on their crystallinity}

Polyacrylic acid and sodium alginate were used to obtain two series of HPMC-based blends. The addition of the polymers to HPMC determined some spectral changes assigned to the intermolecular hydrogen bonds between the blend components. The estimated $\mathrm{H}$-bond interactions by the Sederholm equations ${ }^{16}$ revealed a strong interconnected network between HPMC and PAA, with a calculated H-bond energy of 25.89 $\mathrm{kJ},{ }^{17}$ as compared to the HPMC/SA blends, where the H-bond energy was $19.13 \mathrm{~kJ}$, increasing with an increased content of HPMC. ${ }^{18}$

The IR spectra of the blends revealed similar absorption bands assigned to the $\mathrm{O}-\mathrm{H}$ stretches at $3300-3400 \mathrm{~cm}^{-1}, \mathrm{C}-\mathrm{H}$ asymmetric and symmetric stretches assigned to the methyl and hydroxypropyl groups arising from the substitution of O-H groups at $2800-2900 \mathrm{~cm}^{-1}$, C$\mathrm{O}-\mathrm{C}$ bonds in ether cellulose derivatives found at $1300-900 \mathrm{~cm}^{-1}$ and bands at wavenumbers ranging from $1200 \mathrm{~cm}^{-1}$ to $1500 \mathrm{~cm}^{-1}$, which are specific to the determination of the crystallinity indexes. $^{19}$

The calculated values of crystallinity indexes for the pure HPMC and the developed polymeric blends are indicated in Table 1. One can observe an increase in the TCI value upon addition of PAA and SA from 1.00 (HPMC) to 2.63 (HPMC/PAA) and 2.20 (HPMC/SA), as well as in the LOI value from 0.34 (HPMC) to 4.22 (HPMC/PAA-Ia) and 5.12 (HPMC/SA-IIa), suggesting an increase in the crystallinity degree (TCI) of the HPMC, supported by the H-bond interactions between the polymeric components (HBI), and in the overall degree of order in HPMC (LOI). The formation of the strong interconnected networks is also supported by the HBI values, which increase from $40 \%$ (HPMC) to 98.86\% (HPMC/PAA) and 44\% (HPMC/SA). 
Table 1

Calculated crystallinity indexes for HPMC-based polymeric blends

\begin{tabular}{|c|c|c|c|}
\hline Sample & TCI $\left(\mathrm{A}_{1374} / \mathrm{A}_{2920}\right)$ & LOI $\left(\mathrm{A}_{1416} / \mathrm{A}_{904}\right)$ & $\operatorname{HBI}\left(\mathrm{A}_{3350} / \mathrm{A}_{1337}\right)(\%)$ \\
\hline & \multicolumn{3}{|c|}{$25^{\circ} \mathrm{C}$} \\
\hline HPMC & 1.00 & 0.34 & 40.00 \\
\hline Ia & 2.63 & 4.22 & 98.86 \\
\hline $\mathrm{Ib}$ & 1.38 & 2.40 & 86.00 \\
\hline Ic & 1.33 & 1.60 & 53.84 \\
\hline Id & 1.14 & 1.63 & 45.45 \\
\hline IIa & 2.20 & 5.12 & 44.00 \\
\hline $\mathrm{IIb}$ & 1.16 & 6.00 & 20.00 \\
\hline IIc & 2.66 & 10.75 & 10.00 \\
\hline \multirow[t]{2}{*}{ IId } & 1.71 & 6.28 & 12.50 \\
\hline & \multicolumn{3}{|c|}{$37^{\circ} \mathrm{C}$ (heating) } \\
\hline Ia & 2.00 & 3.45 & 10.52 \\
\hline $\mathrm{Ib}$ & 1.57 & 2.18 & 38.88 \\
\hline Ic & 1.38 & 1.50 & 21.42 \\
\hline Id & 1.40 & 1.50 & 23.52 \\
\hline IIa & 2.40 & 4.44 & 18.18 \\
\hline $\mathrm{IIb}$ & 1.63 & 3.54 & 8.33 \\
\hline IIc & 2.40 & 7.50 & 7.14 \\
\hline \multirow[t]{2}{*}{ IId } & 1.62 & 5.25 & 6.56 \\
\hline & \multicolumn{3}{|c|}{$47^{\circ} \mathrm{C}$ (heating) } \\
\hline Ia & 2.00 & 2.00 & 4.10 \\
\hline $\mathrm{Ib}$ & 1.71 & 1.81 & 8.69 \\
\hline Ic & 1.44 & 1.50 & 10.52 \\
\hline Id & 1.53 & 1.52 & 5.00 \\
\hline IIa & 2.80 & 4.20 & 8.33 \\
\hline $\mathrm{IIb}$ & 1.54 & 3.33 & 6.56 \\
\hline IIc & 2.37 & 5.22 & 6.25 \\
\hline \multirow[t]{2}{*}{ IId } & 2.11 & 4.09 & 5.88 \\
\hline & \multicolumn{3}{|c|}{$55^{\circ} \mathrm{C}$ (heating) } \\
\hline Ia & 1.88 & 1.76 & 4.00 \\
\hline $\mathrm{Ib}$ & 1.66 & 1.66 & 4.16 \\
\hline Ic & 1.50 & 1.41 & 4.76 \\
\hline Id & 1.53 & 1.55 & 4.54 \\
\hline IIa & 2.50 & 4.20 & 9.09 \\
\hline IIb & 1.72 & 3.41 & 6.56 \\
\hline IIc & 2.22 & 4.60 & 6.25 \\
\hline \multirow[t]{2}{*}{ IId } & 1.90 & 4.18 & 5.88 \\
\hline & \multicolumn{3}{|c|}{$47^{\circ} \mathrm{C}$ (cooling) } \\
\hline Ia & 2.13 & 2.12 & 3.84 \\
\hline $\mathrm{Ib}$ & 1.72 & 1.93 & 8.00 \\
\hline Ic & 1.62 & 1.50 & 5.00 \\
\hline Id & 1.61 & 1.47 & 4.76 \\
\hline IIa & 2.50 & 4.20 & 8.33 \\
\hline IIb & 1.63 & 3.63 & 6.56 \\
\hline IIc & 2.25 & 5.00 & 5.88 \\
\hline \multirow[t]{2}{*}{ IId } & 1.75 & 3.38 & 6.25 \\
\hline & \multicolumn{3}{|c|}{$37^{\circ} \mathrm{C}$ (cooling) } \\
\hline Ia & 1.57 & 2.07 & 4.34 \\
\hline $\mathrm{Ib}$ & 1.68 & 1.92 & 15.78 \\
\hline Ic & 1.46 & 1.50 & 11.11 \\
\hline Id & 1.50 & 1.53 & 10.52 \\
\hline IIa & 2.80 & 4.55 & 8.33 \\
\hline $\mathrm{IIb}$ & 1.77 & 3.45 & 8.33 \\
\hline IIc & 2.83 & 4.66 & 6.25 \\
\hline IId & 2.00 & 3.72 & 7.14 \\
\hline
\end{tabular}




\section{Influence of HPMC concentration on the crystallinity of the blends}

The concentration of HPMC in the blends was varied to obtain differently interconnected polymeric blends: HPMC/PAA 1:1 (Ia); 2:1 (Ib); 3:1 (Ic); 4:1 (Id) and HPMC/SA 1:30 (IIa); 2:30 (IIb); 3:30 (IIc) and 4:30 (IId). The deconvoluted IR spectra of HPMC/PAA in the $1500-1200 \mathrm{~cm}^{-1}$ spectral range (Fig. 1) revealed different positions and shapes of the peaks assigned to the $\mathrm{CH}_{2}$ scissoring vibrations at $1410 \mathrm{~cm}^{-1}$, which is useful in the identification of the type of crystalline cellulose. One can observe a blueshift of this band by $6-10 \mathrm{~cm}^{-1}$ in the blends. At the lowest concentration (HPMC/PAA 1:1), two contributions of the $\mathrm{CH}_{2}$ scissoring vibrations can be observed at $1400 \mathrm{~cm}^{-1}$ and at $1412 \mathrm{~cm}^{-1}$, while at higher concentrations of HPMC, the appearance of the band at $1316 \mathrm{~cm}^{-1}$ assigned to the $\mathrm{O}-\mathrm{H}$ bending vibrations can be observed. The calculated TCI and HBI for HPMC/PAA and HPMC/SA blends decreased, suggesting a perturbation in the crystallinity degree of HPMC, caused by the different intra- and intermolecular H-bond formation, also supported by the increased values of LOI (the overall order).
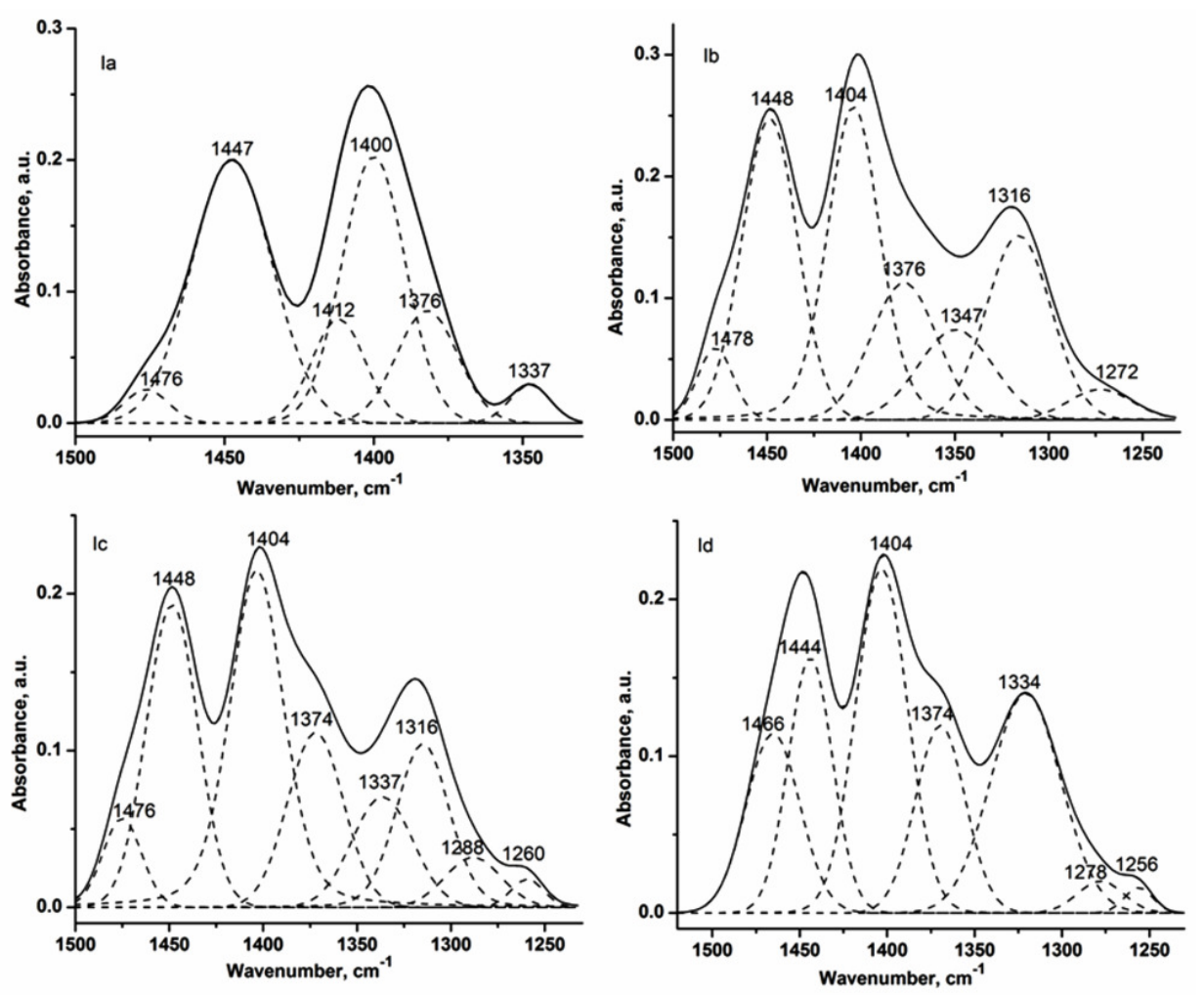
Figure 1: Deconvoluted IR spectra of HPMC/PAA blends in the $1500-1200 \mathrm{~cm}^{-1}$ spectral range

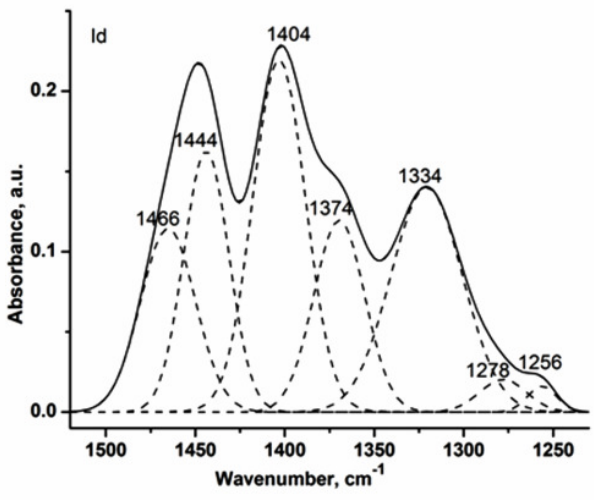

The deconvoluted IR spectra of the HPMC/SA blends in the $1500-1200 \mathrm{~cm}^{-1}$ region also revealed the appearance of the band at $1424 \mathrm{~cm}^{-1}$ redshifted by $4-30 \mathrm{~cm}^{-1}$ at higher concentrations of HPMC, assigned to $\mathrm{CH}_{2}$ scissoring vibrations, suggesting the presence of the ordered crystalline phase in the blend, also supported by the appearance of the band at $1318 \mathrm{~cm}^{-1}$, characteristic of the $\mathrm{O}-\mathrm{H}$ bending vibrations in the IR spectrum of the IIc blend with the highest LOI values (Fig. 2). ${ }^{20}$

\section{Influence of temperature on the crystallinity of the HPMC-based polymeric blends}

The IR spectra of the HPMC/PAA and HPMC/SA blends during the heating and cooling processes in the $25-55^{\circ} \mathrm{C}$ temperature range also evidenced the crystallinity changes. The temperature strongly affects the HPMC/PAA blends due to the higher network flexibility induced by the presence of the PAA component. One can observe an increased intensity of the main bands associated with the crystallinity of blends (Fig. 3).

The deconvolution of the same spectral region allowed identifying the position of the main peaks associated with the crystallinity degree (Figs. 4 and 5). 

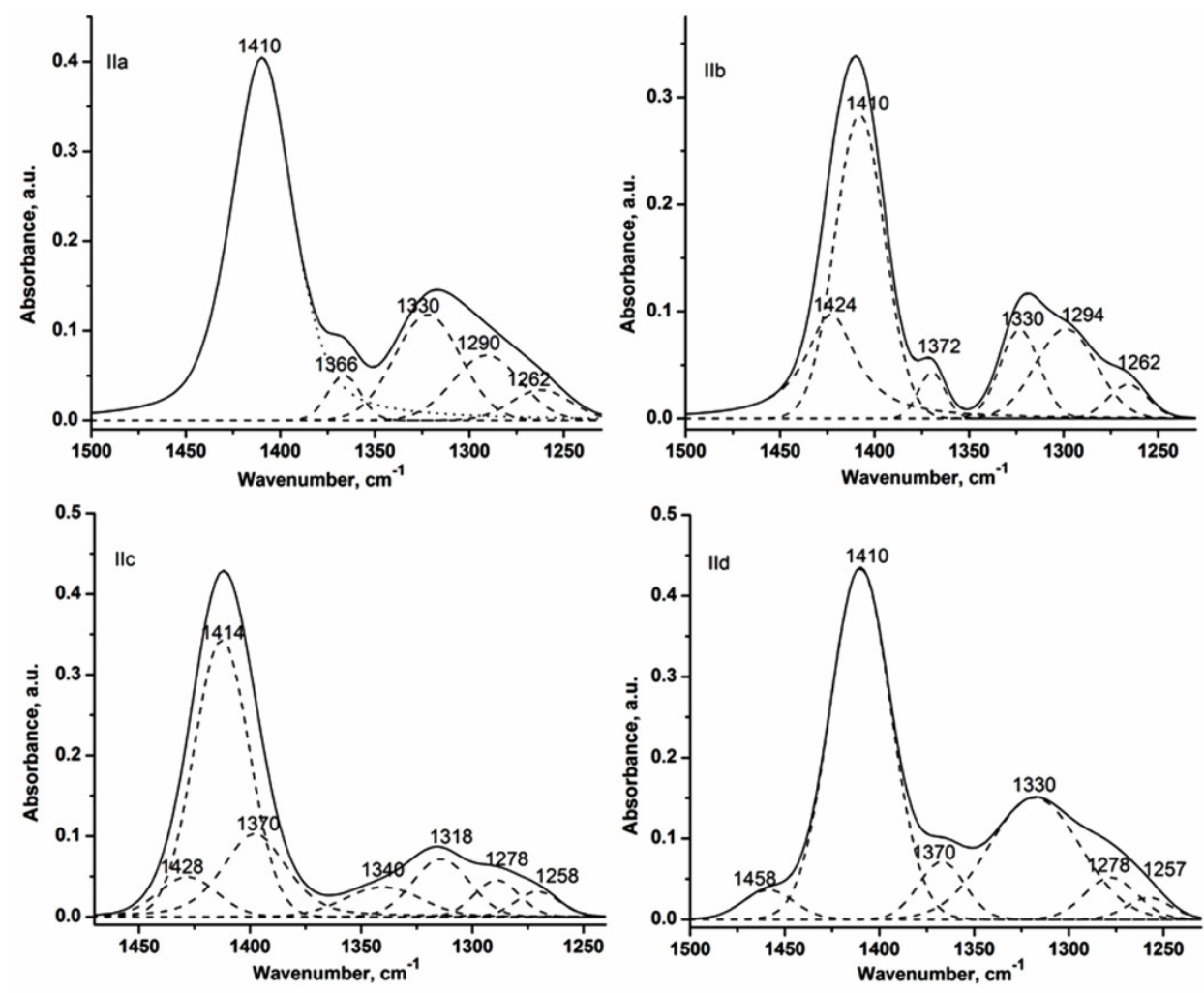

Figure 2: Deconvoluted IR spectra of HPMC/SA blends in the $1500-1200 \mathrm{~cm}^{-1}$ spectral range
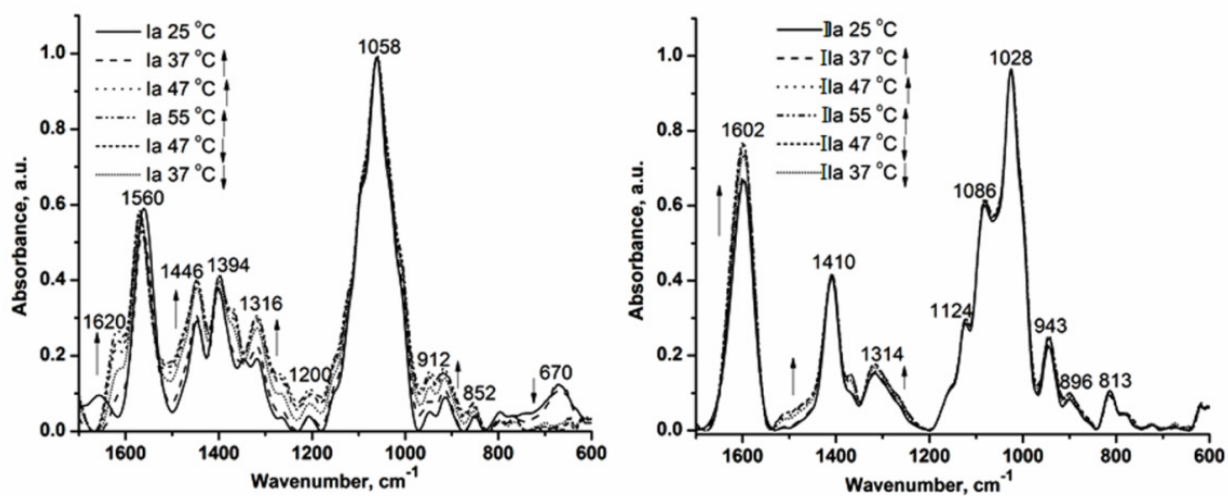

Figure 3: IR spectra of HPMC/PAA-Ia and HPMC/SA-IIa blends during heating and cooling processes from 25 to $55^{\circ} \mathrm{C}$

Thus, heating the blends at $37{ }^{\circ} \mathrm{C}$ resulted in a decrease of the values attributed to LOI and HBI and a slight decrease of the TCI values (Table 1). This is supported by the evolution of the calculated area assigned to the bands at $1374 \mathrm{~cm}^{-}$ $1,1416 \mathrm{~cm}^{-1}$ and $1337 \mathrm{~cm}^{-1}$ (Fig. 6). The overall ordered degree in the HPMC blends at higher temperature is disturbed by the H-bond dissociation as temperature increases, the highest decrease being observed for the Ia blend with a lower HPMC concentration. By heating the blends at $47^{\circ} \mathrm{C}$ and $55^{\circ} \mathrm{C}$, a slight increase of the TCI values at higher concentration of HPMC concentration in blends was observed, while the LOI and HBI values are lower than those calculated at $37{ }^{\circ} \mathrm{C}$, suggesting a strong dissociation of the intermolecular H-bonds between the polymeric blend components. The 


\section{MIRELA-FERNANDA ZALTARIOV}

corresponding calculated areas characteristic of the crystallinity indexes also revealed higher values for the band at $1416 \mathrm{~cm}^{-1}$ and $1337 \mathrm{~cm}^{-1}$, directly associated with the lower values of LOI and $\mathrm{HBI}$, and relatively constant area for the band at $1374 \mathrm{~cm}^{-1}$, characteristic of TCI (Fig. 6).
During the cooling processes, a reversible phenomenon can be observed, as evidenced by the close values of the crystallinity indexes and supported by the reversible and dynamic character of the H-bonds, even if the HBI values are lower.
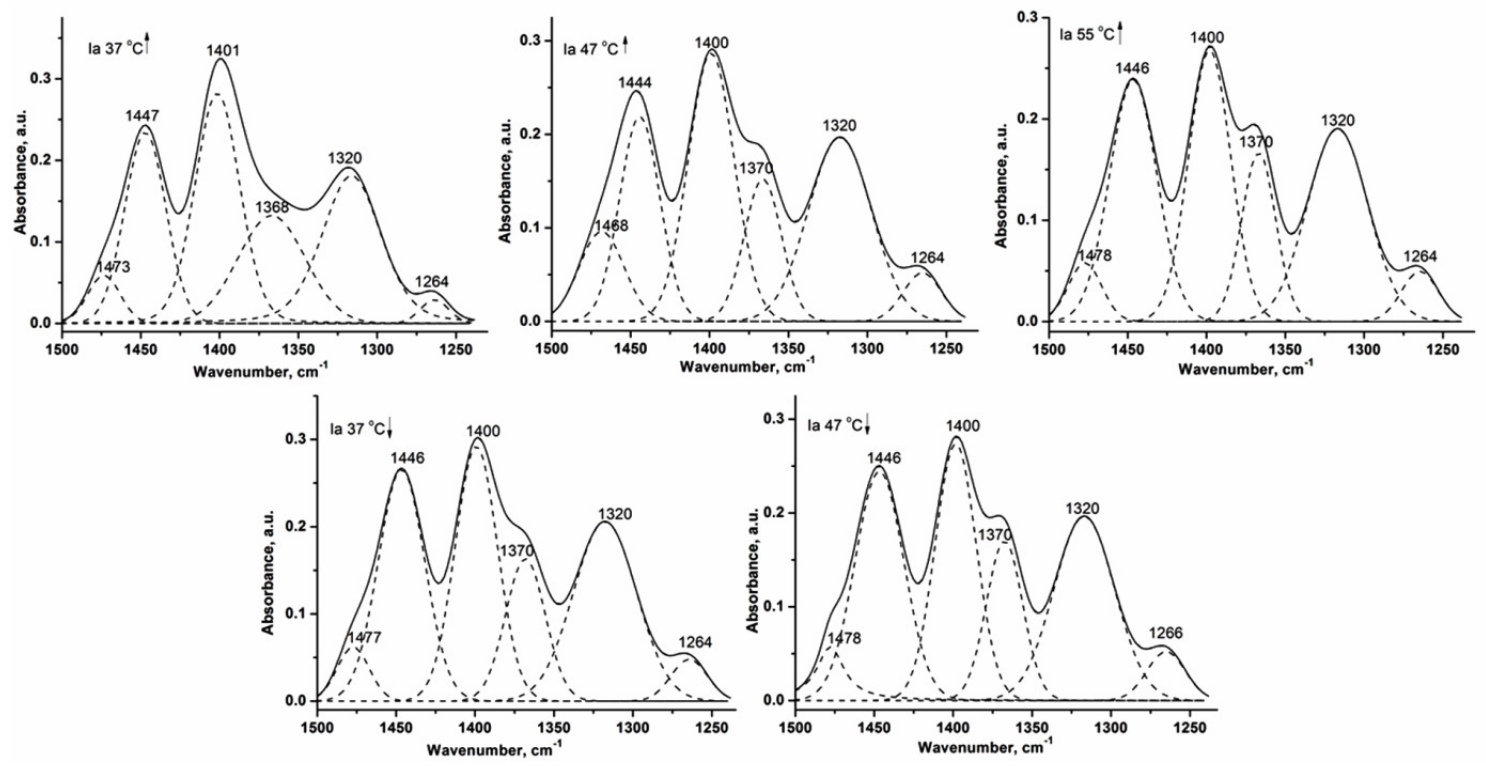

Figure 4: Deconvolution of IR spectra of HPMC/PAA 1:1 (Ia) in the $1500-1200 \mathrm{~cm}^{-1}$ spectral range
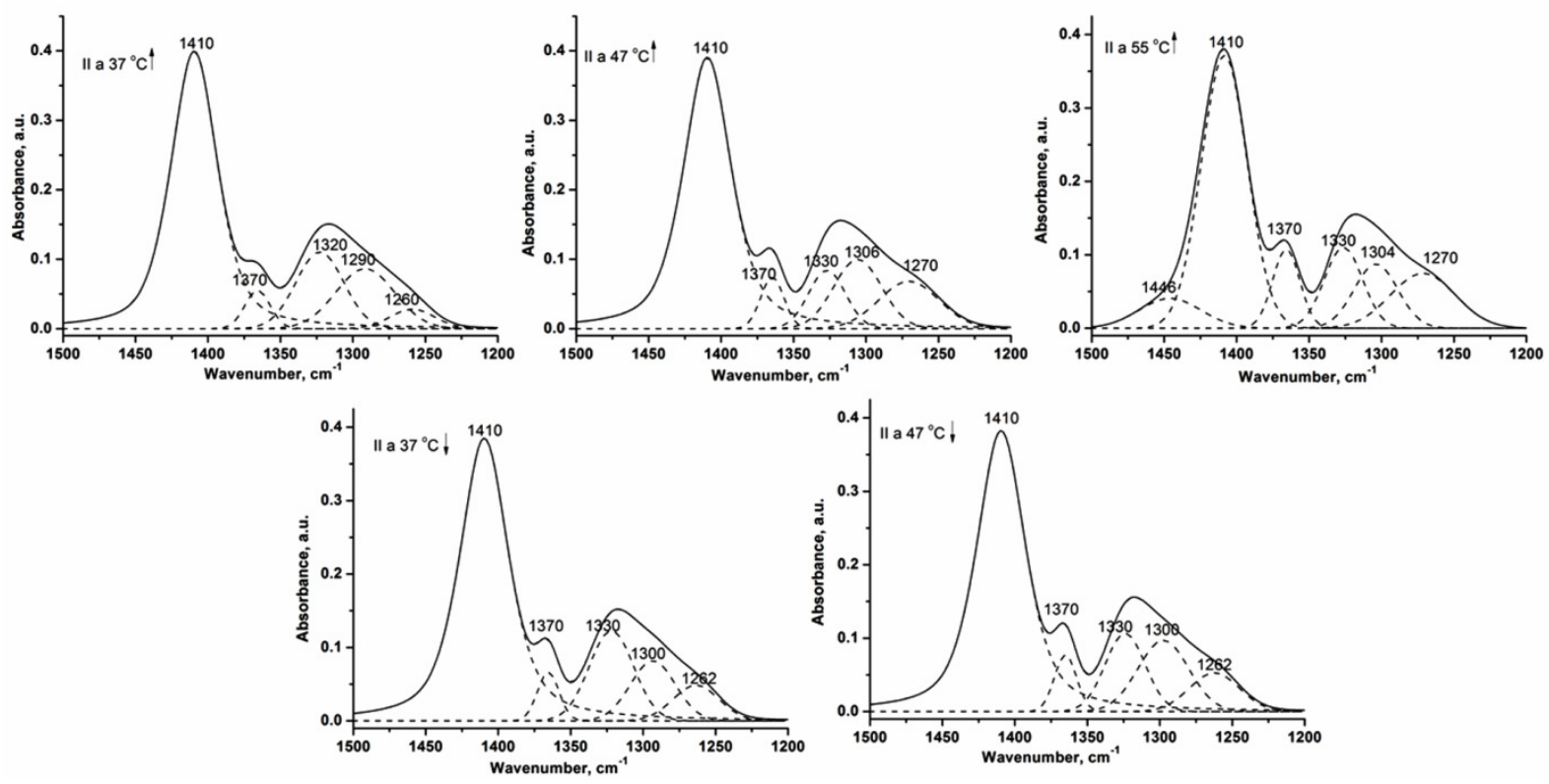

Figure 5: Deconvolution of IR spectra of HPMC/SA 1:30 (IIa) in the 1500-1200 $\mathrm{cm}^{-1}$ spectral range 

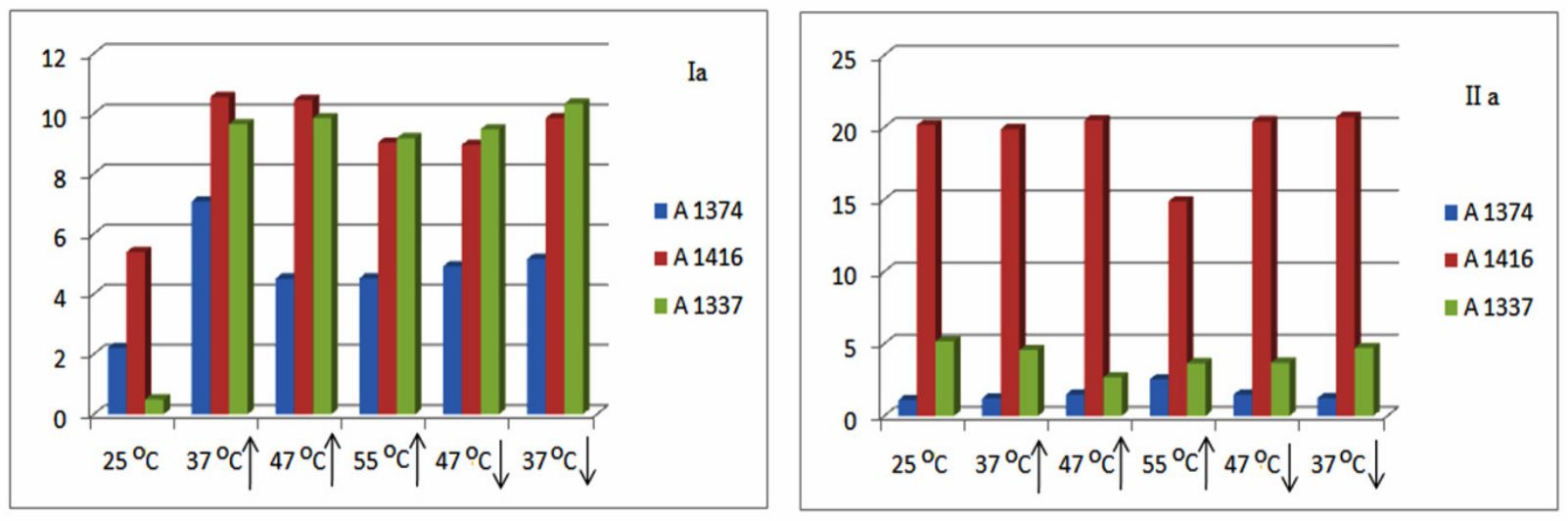

Figure 6: Comparative calculated areas of the bands associated with the crystallinity indexes obtained during heating and cooling processes

\section{CONCLUSION}

ATR-FTIR spectroscopy has been demonstrated as a useful tool for practically assessing the crystallinity degree of hydroxypropyl methyl cellulose in polymeric blends comprising polyacrylic acid and sodium alginate. The identification of the crystalline and amorphous cellulose absorptions in the IR spectra allowed the calculation of TCI, LOI and HBI indexes of the blends as a function of their composition, HPMC concentration and temperature. The crystallinity degree proved to be sensitive to the concentration of HPMC and to heating/cooling processes. The analysis of the crystallinity of HPMC-based polymeric blends offers a new qualitative and quantitative method to evaluate the influence of different factors on their composition.

\section{REFERENCES}

1 R. Ghadermazi, S. Hamdipour, K. Sadeghi, R. Ghadermazi and A. K. Asl, Food Sci. Nutr., 7, 3363 (2019), https://doi.org/10.1002/fsn3.1206

2 P. Kraisit, S. Limmatvapirat, J. Nunthanid, P. Sriamornsak and M. Luangtana-Anan, Chem. Pharm. Bull., 65, 284 (2017), https://doi.org/10.1248/cpb.c1600849

3 H. Somashekarappa, Y. Prakash, K. Hemalatha, T. Demappa and R. Somashekar, Indian J. Mater. Sci., 2013, Article ID 307514 (2013), http://dx.doi.org/10.1155/2013/307514

4 E. Karavas, E. Georgarakis and D. Bikiaris, Eur. J. Pharm. Biopharm., 63, $103 \quad$ (2006), https://doi.org/10.1016/j.ejpb.2006.01.016

5 G. Maffione, P. Iamartino, G. Guglielmini and A. Gazzaniga, Drug Dev. Ind. Pharm., 19, 2043 (1993), https://doi.org/10.3109/03639049309069340
6 Siddaramaiah, P. Kumar, K. H. Divya, B. T. Mhemavathi and D. S. Manjula, J. Macromol. Sci., Part A: Pure Appl. Chem., 43, 601 (2006), https://doi.org/10.1080/10601320600575231

7 M. L. Nelson and R. T. O'Connor, J. Appl. Polym. $\begin{array}{llll}\text { Sci. } & \mathbf{8} & 1325 & \text { (1964), }\end{array}$ https://doi.org/10.1002/app.1964.070080323

8 M. L. Nelson and R. T. O'Connor, J. Appl. Polym. Sci., $\quad \mathbf{8}, \quad 1311 \quad$ (1964), https://doi.org/10.1002/app.1964.070080322

9 A.-A. M. A. Nada, S. Kamel and M. El-Sakhawy, Polym. Degrad. Stab., 70, 347 (2000), https://doi.org/10.1016/S0141-3910(00)00119-1

10 S. Park, J. O. Baker, M. E. Himmel, P. A. Parilla and D. K. Johnson, Biotechnol. Biofuels, 3, 10 (2010), http://www.biotechnologyforbiofuels.com/content/3/1/ 10

11 I. Spiridon, C. A. Teacă and R. Bodîrlău, BioResources, $\quad$ 6, $400 \quad$ (2011), https://doi.org/10.15376/biores.6.1.400-413

12 C. A. Teaca, R. Bodîrlău and I. Spiridon, Carbohyd. Polym., 93, $307 \quad$ (2013), https://doi.org/10.1016/j.carbpol.2012.10.020

13 I. Spiridon, I.-M. Andrei, N. Anghel, M. V. Dinu and B.-I. Ciubotaru, Polymers, 13, 2176 (2021), https://doi.org/10.3390/polym13132176

${ }_{14}$ C. A. Gafitanu, D. Filip, C. Cernatescu, D. Rusu, C. G. Tuchilus et al., Pharm. Res., 34, 2185 (2017), https://doi.org/10.1007/s11095-017-2226-Z

15 A. Kljun, T. A. S. Benians, F. Goubet, F. Meulewaeter, J. P. Knox et al., Biomacromolecules, 12, 4121 (2011), https://dx.doi.org/10.1021/ bm201176m

16 G. C. Pimentel and C. H. Sederholm, J. Chem. Phys., 24, 639 (1956), https://doi.org/10.1063/ 1.1742588

17 M.-F. Zaltariov, D. Filip, C.-D. Varganici and D. Macocinschi, Cellulose Chem. Technol., 52, 619 (2018), https://www.cellulosechemtechnol.ro/ pdf/CCT7-8(2018)/p.619-631.pdf 


\section{MIRELA-FERNANDA ZALTARIOV}

18 M.-F. Zaltariov, B.-I. Ciubotaru, L. Vereștiuc, D. Peptanariu, D. Macocinschi et al., Cellulose Chem. Technol., $\quad 53, \quad 869 \quad$ (2019), https://doi.org/10.35812/CelluloseChemTechnol.2019. 53.84
19 C. G. Otoni, M. V. Lorevice, M. R. de Moura and L. H.C. Mattoso, Carbohyd. Polym., 185, 105 (2018), https://doi.org/10.1016/j.carbpol.2018.01.016

20 L. Alves, B. Medronho, F. E. Antunes, M. P. Fernández-García, J. Ventura et al., J. Mol. Liq., 210, $106 \quad$ (2015), http://dx.doi.org/10.1016/ j.molliq.2014.12.010 